This item was submitted to Loughborough's Institutional Repository by the author and is made available under the following Creative Commons Licence conditions.

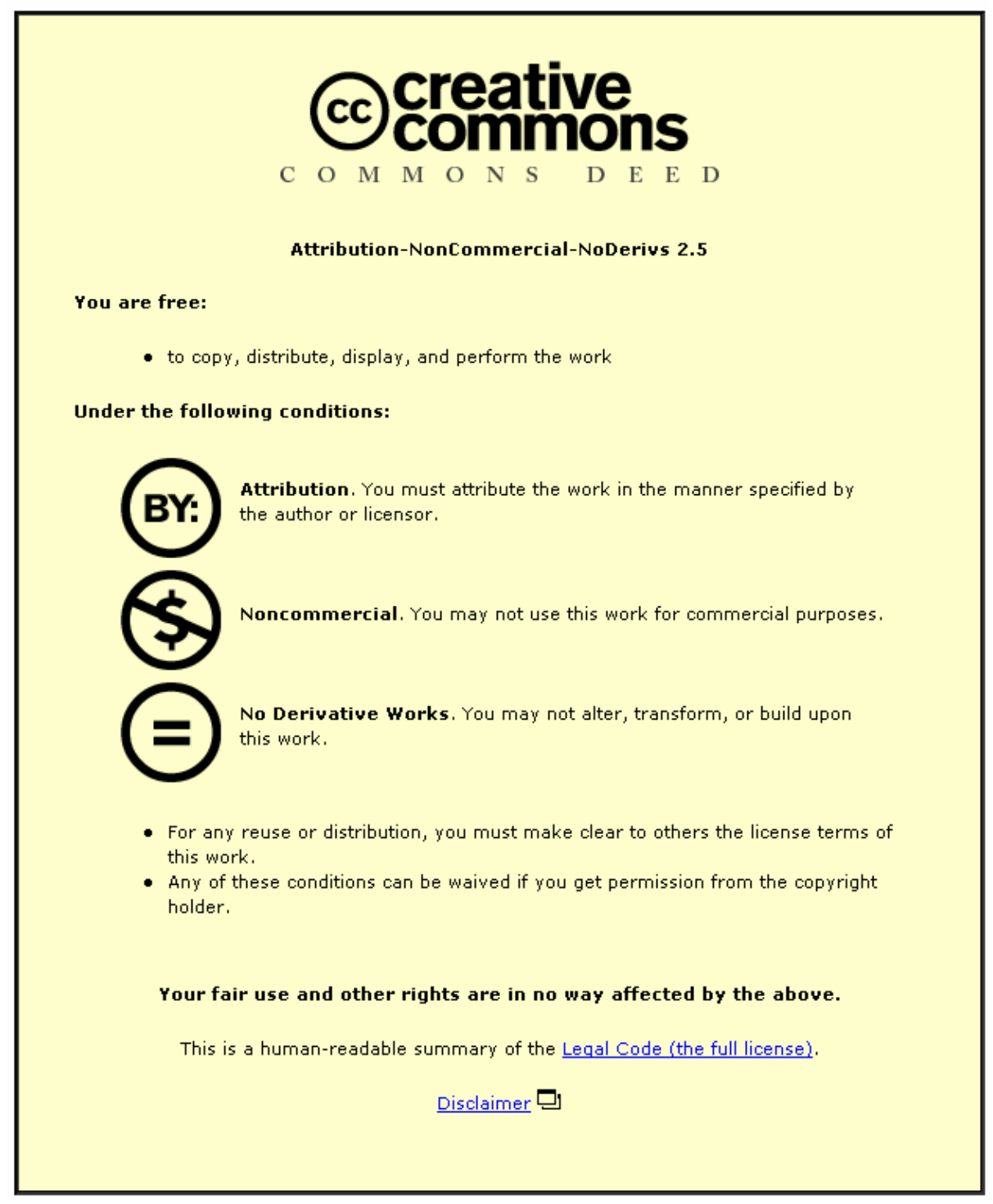

For the full text of this licence, please go to: http://creativecommons.org/licenses/by-nc-nd/2.5/ 


\title{
THE DEVELOPMENT AND APPLICATION OF A SIMPLE METHODOLOGY FOR RECORDING ROCK ART USING CONSUMER-GRADE DIGITAL CAMERAS
}

\author{
JiM H. CHANDLER (j.h.chandler@lboro.ac.uk), \\ Loughborough University \\ PAUL BRYAN(Paul.Bryan@english-heritage.org.uk), \\ English Heritage \\ JOHN G. FrYER (john.fryer@newcastle.edu.au), \\ University of Newcastle, Callaghan, NSW, Australia
}

(Based on a contribution to the Annual Conference of the Remote Sensing and Photogrammetry Society at Fitzwilliam College, Cambridge, on 8th September, 2006)

\begin{abstract}
A simple methodology for recording rock art has been recently developed in Australia and tested on aboriginal rock art, including both petroglyphs and pictographs (engraved and painted images respectively). The approach was based upon commercial photogrammetric software and consumer-grade digital cameras, because it was believed that archaeologists, conservators and site managers need simple and cost-effective methods to record and document rock art. This methodology has been adopted subsequently by the Northumberland and Durham Rock Art Project working in conjunction with English Heritage, to assist in recording 1500 prehistoric engraved panels located across the north-east of England. Significantly, the field work is carried out by enthusiastic volunteers, willing to sacrifice their weekends to capture imagery suitable for digital photogrammetry.

This paper explains briefly how the recording technique was developed in Australia before indicating how expertise and equipment was integrated to allow UK-based volunteers to carry out data acquisition and, perhaps surprisingly, also the photogrammetry. This will demonstrate the value of mobilising the voluntary sector for heritage recording, which is feasible only if recording methodologies are based on cheap and simple instrumentation.
\end{abstract}


KEYWORDS: consumer-grade digital cameras, DEMs, heritage recording, orthophotographs, petroglyphs, rock art

\section{INTRODUCTION}

ROCK ART IS FOUND throughout the world and represents one of the few physical traces left by ancient civilisations that are directly accessible. The creation of some sort of facsimile of rock art is desirable, allowing for its scientific study and providing some protection against loss in the event of destruction. The purpose of this paper is to outline the development of a recording methodology based on photogrammetry and using cheap, consumer-grade digital cameras. The paper also demonstrates that, with appropriate training, such simple techniques can be adopted and used for extensive and systematic recording of rock art by volunteers with little or no experience of photogrammetry.

\section{PAST WORK AND TECHNOLOGIES}

Two forms of rock art are recognised (Rosenfeld, 1988). Engraved features, where rock has been scraped or pecked away in a subtractive process, are known as petroglyphs. The more familiar additive form of image, where a variety of pigments are applied to the rock surface, is described as a pictograph. Traditionally, three methods have been used to record rock art: freehand drawing, tracing and photography (Stanbury and Clegg, 1990). Although of increasing sophistication, all suffer from various limitations relating to accuracy, the need to touch a potentially fragile object and the time required in the field. Consequently, methods based on photography have remained universal (Clogg et al., 2000). Recording rock art in three dimensions has obvious benefits and most recently laser scanning has appeared to offer great potential (Goskar et al., 2003), particularly for recording heritage sites (Boehler et al., 2001; Neubauer et al., 2005). However, despite their many advocates, scanners remain bulky and expensive, they are affected by surface reflectance properties and they are not easy to operate (El-Hakim et al., 2005).

Photogrammetry has been used to record rock art in the past. Atkinson used a special stereometric camera system and Thompson-Watts plotter to record small petroglyphs at Stonehenge (Atkinson, 1968). In a series of projects, Rivett (1983) and Ogleby and Rivett (1985) demonstrated the benefits of photogrammetry for recording rock art, both petroglyphs and pictographs. Fieldwork was conducted at a series of sites around Australia, including Kakadu National Park, Northern Territory; Whale Cave, NSW; Quinkin, Queensland; Hawkesbury, NSW; and various cave sites in Western Australia. Their Handbook of Heritage Photogrammetry (Ogleby and Rivett, 1985) was a key text of its day, describing how to conduct a photogrammetric survey for field archaeology. More recently, Ogleby $(1995$; 1999) has continued to demonstrate the benefits of photogrammetry to a wider archaeological audience, particularly the Ayutthaya temple in Thailand (Ogleby, 1999). 
The International Committee for Architectural Photogrammetry (CIPA) was established to improve the recording of cultural monuments using photogrammetry. One of the important principles adopted has been the " $3 \times 3$ " method of image acquisition (Waldhäusl and Ogleby, 1994) to promote the acquisition of photography and records that allow photogrammetric measurement. The principles include three geometrical rules (control, base/distance ratio, normal photography); three photographic rules (constant camera geometry, soft illumination, film type); and three organisational rules (sketches, care, checks). It is disappointing that these principles and photogrammetric methods have not been more widely adopted. Indeed, one of the tasks identified by CIPA is to "bridge the gap" (Letellier, 2001) between the information user and the information provider. It is recognised (Palumbo and Ogleby, 2004) that the chief obstacle to the wider adoption of photogrammetry for rock art recording is the non-availability of cheap, portable, automated and easy-to-use systems. The work described in this paper demonstrates that a significant step towards that objective has now been achieved.

\section{THE TECHNIQUE}

During a six-month period of study leave spent in Australia, the first author working in conjunction with the third developed a simple methodology for recording aboriginal rock art. This combined the use of consumer-grade digital cameras, simple control and commercial digital photogrammetric software to extract digital elevation models (DEMs) and orthophotographs and to create flythrough models. This combination appeared prudent, because of the need to ensure that field equipment was light, robust and simple to operate. These authors had already been demonstrating the potential of consumergrade digital cameras (Chandler et al., 2005a) and cheap sensors seemed ideally Discussions with specialists in rock art (personal communications: Taçon, 2004; Ogleby, 2004) revealed the need for cost-effective solutions, particularly if recording could be conducted by those with rock-art expertise and without extensive training. A full description of the technique and its

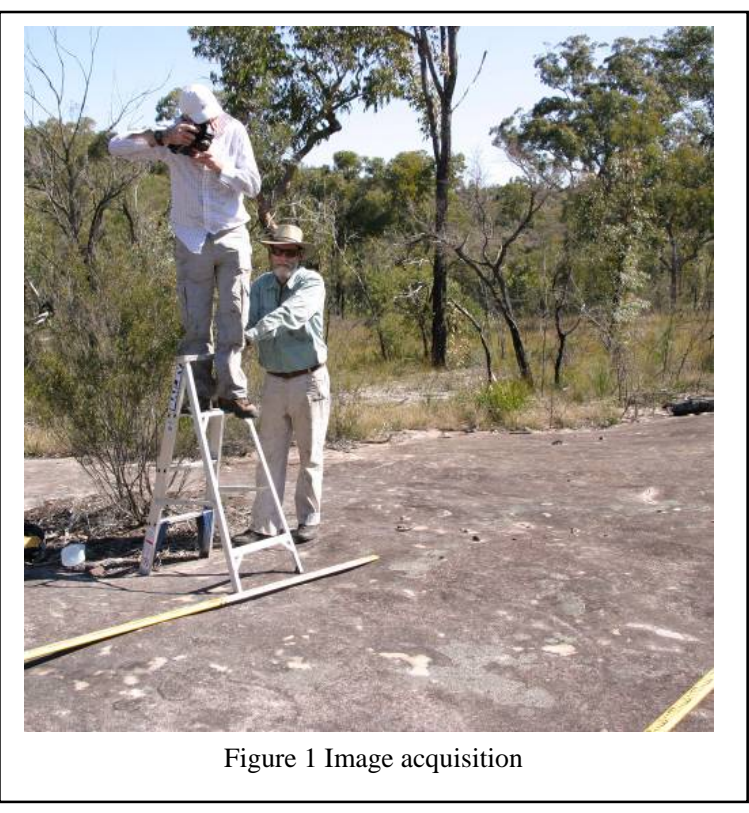


development has been documented elsewhere (Chandler and Fryer, 2005; Chandler et al., 2005b) and so only brief details are required here.

\section{Image acquisition}

The developed methodology uses the humble stereopair as the basic building block to provide stereoscopic coverage of rock-art sites, suitable for recording both petroglyphs and pictographs. For many simple sites, a single stereopair is theoretically all that is required, but multiple stereopairs provide redundancy, increased coverage and additional viewpoints. Normal accepted "base to distance" ratios need to be maintained, typically between 1:3 and 1:6 if DEM extraction is envisaged. If simple stereoviewing only is required, the recommended base to distance ratio would be between 1:6 and 1:12. Conventional image pairs which are normal to the object (that is, with both camera axes perpendicular to the approximate plane of the object) can be acquired, but the author has obtained very good results with convergent imagery, provided that the camera axes do not cross. If lighting permits, images can be acquired using a handheld camera, (Figure 1), otherwise a modest camera tripod is required. A wide variety of consumer-grade digital cameras can be used; the author had access only to a three megapixel Nikon (Coolpix 3100) during initial testing in Australia. This cost $£ 200$ in 2004 but similar funding today (August 2006) could provide a six megapixel camera. Consumer-grade digital cameras, such as this Nikon, are equipped with a variable zoom and auto-focus lens. The widest zoom setting should be adopted, this provides the largest object coverage and simplifies camera calibration procedures, particularly if object distances are greater than 30 to 50 times the camera focal length (Brown, 1972; Chandler et al., 2005a). For example, with a typical focal length for a digital camera of $6 \mathrm{~mm}$, this equates to a camera-object distance exceeding $300 \mathrm{~mm}$, a situation which is most likely.

\section{Control}

Control can be of two forms. The simplest is to employ a scale bar, which allows final data to be extracted to a known scale. Furthermore, if the scale bar can be placed horizontally it is generally possible to extract data within a coordinate system that is approximately related to the local vertical. If the object is too large to be captured using a single stereopair, or extracted data needs to be oriented exactly to the local

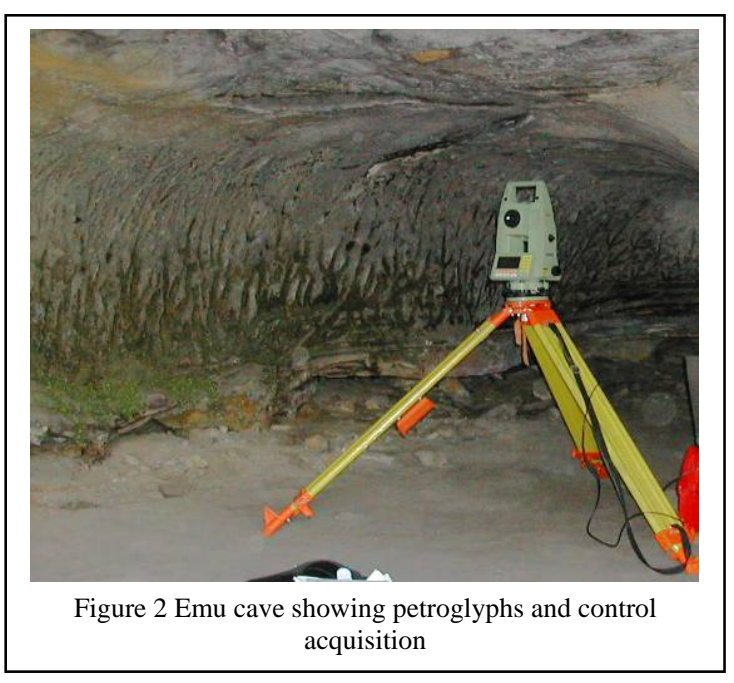


vertical or other reference datum, then targeted control should be adopted. Targets can be stuck temporarily to non-engraved sections of the rock surface using silicone bathroom sealant and then removed easily after the photographs have been acquired. The three-dimensional coordinates of each target need to be determined using either a theodolite intersection method or reflectorless EDM (Figure 2). Simple taping between targets and height differences measured using a level and staff can also be used to determine the location of the control points, when site conditions permit.

\section{Photogrammetric data processing}

Data processing was carried out originally using the Leica Photogrammetry Suite (LPS) (Leica Geosystems, 2005) but any commercial digital photogrammetric software should be capable of creating DEMs and orthophotographs from each stereopair, once satisfactory exterior orientations have been achieved. This procedure is comparatively routine but the use of nonmetric imagery necessitates the calibration of inner camera geometry. The authors had previously identified difficulties with the self-calibrating routines within OrthoBASE PRO and LPS version 8.7 (Chandler, et al., 2005a) and an external self-calibrating bundle adjustment (Chandler and Clarke, 1992) was used to derive focal length, principal point offset and radial lens distortion. Subsequent discussions with Leica have resolved the problems with the self-calibrating capabilities of LPS (Chandler and Fryer, 2005) and future releases (LPS version 9.0) now have the capability of deriving acceptable camera geometry. DEM generation is an automated procedure, capable of generating many thousands of points to represent the object. The LPS algorithm identifies interest points for automated matching and this does require suitable texture and contrast in the image.

\section{APPLICATION}

\section{Australian petroglyphs and pictographs}

Initial development of the technique was achieved using three engraved sites in the Yengo National Park, New South Wales (NSW) (Chandler and Fryer, 2005) and a large pictograph located near the village of Broke in the same state, (Fryer et al., 2005). Success enjoyed at these sites encouraged the authors to propose the technique to David Lambert of the National Parks and Wildlife Service of NSW, responsible for rock art; and Dr Paul Taçon, an anthropologist then working at the Australian Museum, Sydney.

The ideas were enthusiastically received by both, with Taçon remarking "this is exactly the technique we've been waiting for". Three further field sites were subsequently selected and recorded with their assistance, to prove the concept. A series of engravings near Gosford together with nearby "Swinston's Cave" were captured in one single day, demonstrating the efficiency of the recording methodology. Swinston's Cave was particular remarkable because it consists of 
over 200 handprints and motifs, (Chandler and Fryer, 2005). A second field trip to the Blue Mountains west of Sydney allowed the recording of the curious "Emu Cave" (Figure 2). This consists of a series of engraved markings similar to emu footprints and believed to be a totem used to represent one particular group of aborigines who lived in the area until the nineteenth century. This site was recorded using seven pairs of images and small stick-on targets, coordinated using a reflectorless total station. DEMs, orthophotographs and fly-through models were generated using the LPS software (Figure 3). The resolution of the DEMs was

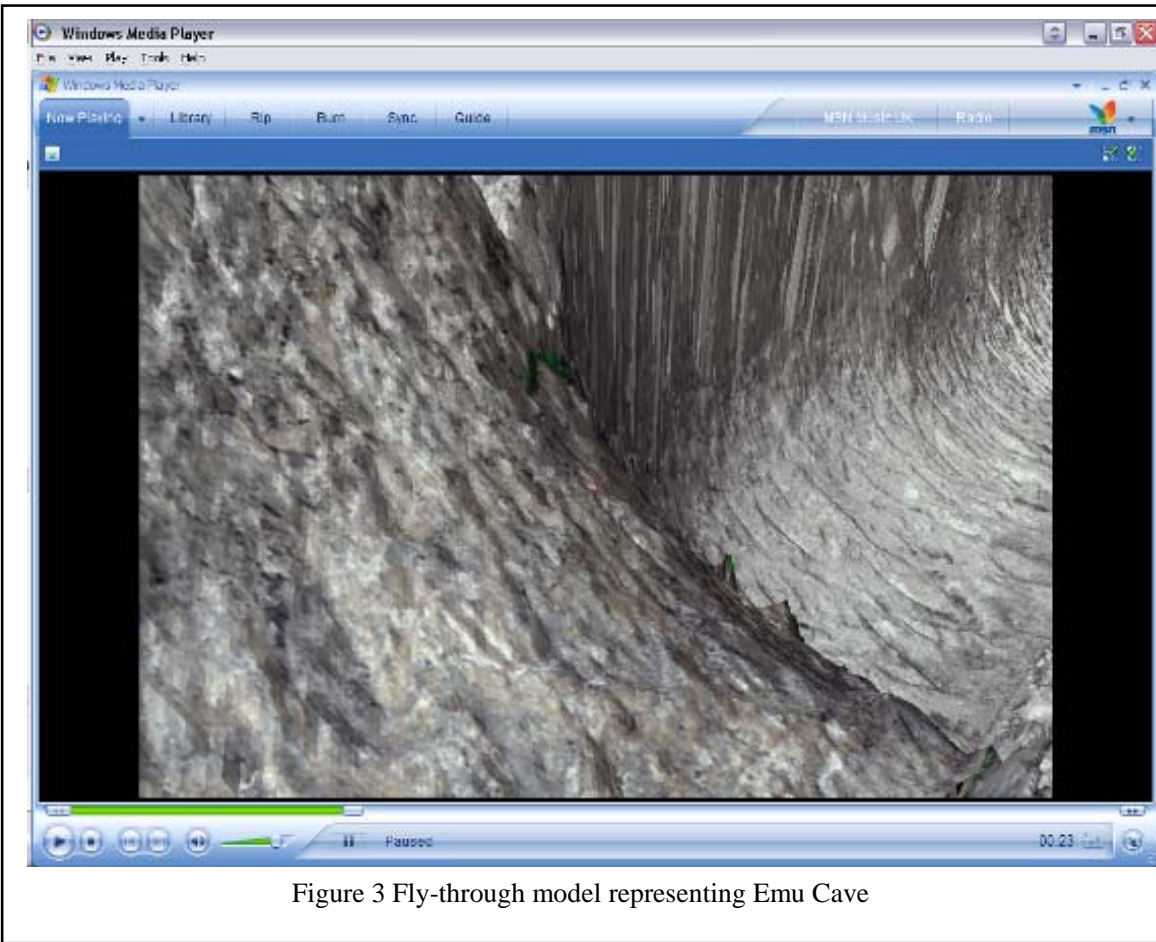

$5 \mathrm{~mm}$, sufficient to capture the detailed 3D morphology of the larger engravings, as well as the gross morphology of the cave wall.

\section{Northumberland and Durham Petroglyphs}

The Northumberland and Durham Rock Art Project is a two-year pilot collaboration between English Heritage and the County Councils of Northumberland and Durham (Barnett, 2006). Its key aim is to recruit and train volunteers to record all 1500 prehistoric engravings located in the north-east of England. Within the project there was scope to trial different methods, including laser scanning and photogrammetry, and identification of an appropriate methodology would have implications for any subsequent national recording initiatives.

The Northumberland and Durham Rock Art Project started about the same time as the Australian study and early success in the latter suggested that a simple 
recording method based on consumer-grade digital cameras and digital photogrammetry was ideal. Following discussions, the English project invested in six Nikon Coolpix 5400 digital cameras (5 megapixel) each costing £240 when purchased in January 2005. In April 2005, the first author ran a one-day workshop in Durham attended by 50 enthusiastic rock-art volunteers. Four presentations were given. The first two described how cheap digital cameras were used to record petroglyphs and pictographs in Australia. This was followed by an explanation of how to acquire appropriate stereo-imagery, emphasising how the base to distance ratio provides a simple guide for success. The final presentation focused on how to use the LPS to extract DEMs and orthophotos (Leica Geosystems, 2005), but also made the point that the stereo-imagery itself could remain the record, rather than any extracted data. The workshop was crucial because it fired enthusiasm, and within weeks the volunteers had begun to go out and acquire imagery. Further advice and encouragement proved necessary and Paul Bryan at English Heritage gave support by e-mail and indeed went out into the field to give further instruction over the summer of 2005.

The six Nikon Coolpix 5400 digital cameras were initially calibrated at Loughborough University in July 2005. The calibration procedure involved acquiring six images of a 3D and planar testfield specifically constructed for this project. The control field design was similar to that used previously (Chandler et al., 2005a) but was slightly larger $(1.2 \times 0.9 \mathrm{~m})$ to allow the cameras to be calibrated at an object distance of $1.5 \mathrm{~m}$. One of the benefits of gaining access to these six cameras was to assess both the temporal stability and manufacturing conformity associated with this particular camera type. The six cameras have recently been calibrated again (June 2006) and the outcome of this work will be the subject of another paper that is in preparation.

Since June 2005 the six Coolpix cameras have been used on a weekly basis to record petroglyphs in Durham and Northumberland. To date (July 2006), imagery of 900 of the 1500 petroglyphs has been captured and fieldwork is nearing completion. The volunteers have experienced a steep learning curve, but after becoming used to the camera settings and having overcome the fear of making a mistake, they are now recording successfully and routinely.

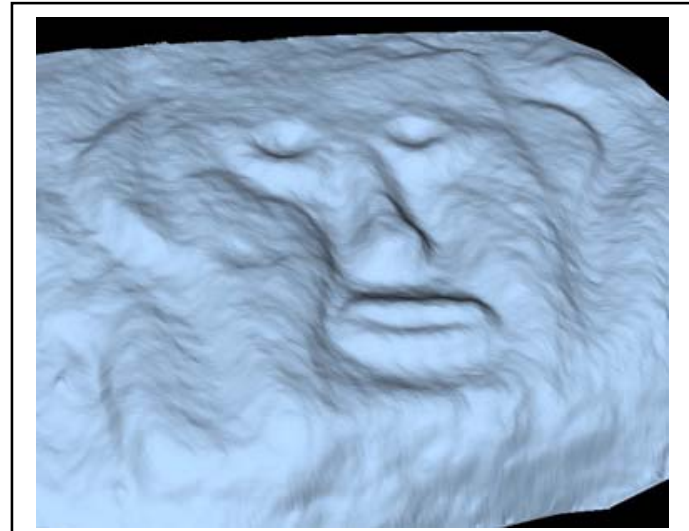

Figure 4- Shaded DEM representing rock-art The larger panels consisting of multiple petroglyphs have caused most problems. Full three-dimensional control is then required and more images are necessary, but assistance by English Heritage in establishing control has helped overcome any confusion. As predicted, most sites have been recorded using a simple scale bar 
for control, combined with multiple stereopairs to provide different look directions and some data redundancy.

Originally, it was envisaged that photogrammetric data extraction would be carried out for just a few exemplars. However, many of the volunteers have become so interested in the technique and procedures, that it is now expected that DEMs and orthophotos will be extracted for all but a few less significant sites. The volunteers have also made universal use of the PI-3000 Pro Image Surveying Station software (Topcon, 2006) rather than LPS and have generally become

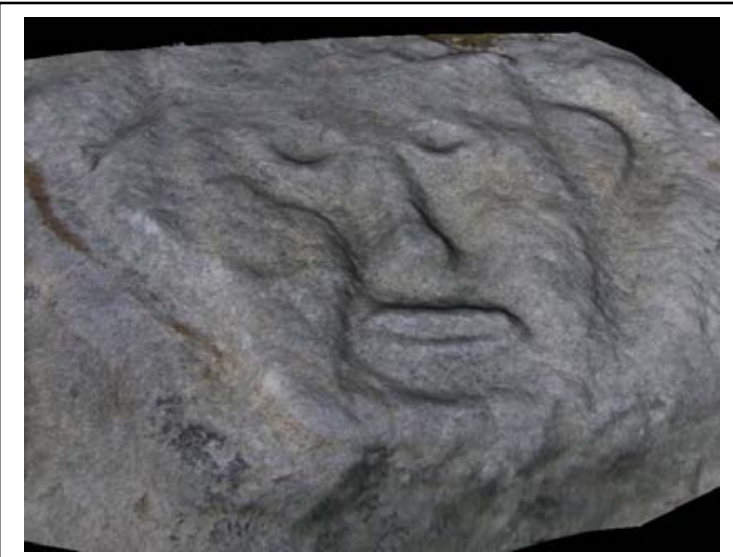

Figure 5- Draped orthophoto representing rock-art proficient in its use for basic DEM (Figure 4) and orthophoto creation (Figure 5). It is expected that all data acquisition will be completed by the end of the project in July 2007, when approximately $12 \mathrm{~Gb}$ of project data will be placed on a server. Detailed planning of this phase is yet to be finalised, but general internet access to some case studies is envisaged.

\section{DISCUSSION}

Photogrammetric experts may be dismissive of the approach described in this paper, by suggesting that there is little novelty in the techniques that have been applied. Digital cameras have provided imagery suited for spatial measurement for over a decade (Shortis and Beyer, 1996). Mathematical models suitable for compensating for degrading systematic effects have been established even longer, thanks to the work of Brown (1972) and Kenefick et al, (1972). Use of cheap consumer-grade digital cameras for spatial measurement is an obvious development, one that is being conducted in parallel by many photogrammetric research facilities across the world (Ogleby et al., 1999; Bosch et al, 2005; Grussenmeyer et al., 2001; Chandler et al., 2003, 2005a; Cardenal et al., 2004). Finally, the use of photogrammetry to record rock art is certainly not novel, the work of Rivett and Ogleby during the 1970s and 80s being particularly noteworthy (Ogleby and Rivett, 1985). Since then, the conference proceedings of CIPA provide ample examples where imagery is being used to record (Peipe and Stephani, 2003; El-Hakim et al., 2005) and in some instances, even recreate, (Grün et al., 2004) our heritage. Patias (2007) provides a full review for the heritage sector and Remondino and El-Hakim (2006) review the current status of three-dimensional image-based modelling.

Despite the existence of this wealth of photogrammetric literature, the harsh reality is that much of this work is being ignored and too many practitioners 
involved in recording rock art are simply not using photogrammetric methods. Invariably, basic methods like sketching, tracing and photography remain dominant (personal communication: Taçon, 2004). The authors believe that this is for two reasons. First, the photogrammetric community appears to be poor at publishing its findings outside mainstream photogrammetric channels. For example, during a literature review investigating the extent to which photogrammetry has been used to record rock art, no instances of photogrammetry could be traced in journals which specialise in rock art and archaeology (Rock Art Research; Journal of Archaeological Science; Australian Archaeology; Internet Archaeology). Secondly, there is always the unstated, but real, competition between photogrammetric researchers, which means that the evidence of research novelty provides the only opportunity for presentation and publication. Researchers write to impress each other and tend to baffle, rather than inform, the casual reader who may be considering using these techniques. As a result, nonphotogrammetrists are discouraged and retain the tried and tested techniques that they fully understand.

The only exception to this is when new technologies are introduced, which tend to entice and seduce all concerned. The excitement engendered by the introduction of laser scanning to heritage recording provides a useful illustration (Boehler et al., 2001; Goskar et al., 2003; Neubauer, et al., 2005). There can be no doubt that point clouds derived by laser scanning, are denser, more precise and more rapidly recovered in the field than is possible with photogrammetric methods. However, does this mean that laser scanning is the right technique in all situations? There are other issues such as cost, ease of use, portability, reflectance and power (Fryer et al., 2005; El-Hakim et al., 2005) which restrict the number of potential applications of the laser. The Northumberland and Durham Rock Art Project put laser scanning to the test and concluded that costs could only be justified at two or three sites out of 1500 , and then only for monitoring erosion. The advantages of a recording method based on cheap digital cameras are clearly low-cost and simplicity. The cost benefit arising from cheap hardware is obvious, but the rock-art recording project has also demonstrated real benefits of simplicity. The ability to mobilise the voluntary sector to carry out the recording is tremendously beneficial. Not only are labour-related costs minimised but other less obvious benefits can be accrued. Recording work can be conducted by local organisations, assisting in developing public understanding of the historic environment and helping to bring it other people's notice. These latter concepts are enshrined as future corporate research strategies for English Heritage (English Heritage, 2005) and although they are difficult to quantify financially they are politically significant in setting the heritage agenda for the first decades of the twenty-first century.

It is also important not to underestimate the capability of the enthusiastic volunteer, particularly when using simple photogrammetric methods and modern photogrammetric software. Originally, it was envisaged that volunteers would carry out photo acquisition only, and although DEMs and orthophotos would be extracted for a few sites, the imagery and control would form the "record". What has proved remarkable about the Northumberland and Durham Rock Art Project has been the enthusiasm to extract data from all of the 1500 recorded sites before 
the completion of the project. Typically, one or two members of each of the six teams has taken responsibility for this process and they now regard the activity of extracting DEMs and orthophotos and generating fly-through displays as routine. Some of the credit for this must of course go to the developers of the commercial photogrammetric software now in use, and, in particular, software engineers at Topcon and Leica Geosystems. Despite this positive message, the cost of commercial photogrammetric software is a significant obstacle to the further use of photogrammetric or image-based modelling (Remondino and El-Hakim, 2006, Chandler and Fryer, 2005). LPS was used for the work conducted in Australia because of the significant discount available for academic use. LPS proved too expensive for the Northumberland and Durham Rock Art Project and it was fortunate that access to the slightly cheaper Topcon package was provided by English Heritage.

\section{CONCLUSION}

This paper has demonstrated forcefully that with appropriate integration of technology and expertise, cost-effective solutions to heritage recording can be developed. The value of using the voluntary sector is unquestionable; encouraging local communities to care for their historic environment by being actively involved is recognised (English Heritage, 2005) and of course, labour costs are minimised. However, mobilising the voluntary sector for heritage recording is feasible only if recording methodologies are based on cheap and simple instrumentation. Laser scanning may provide high-resolution data but it is currently too expensive, bulky and difficult to use by? the layperson. Stereoscopic data acquisition using cheap digital camera technology can be taught comparatively easily and modern digital photogrammetric software is easier to use than many people may imagine, particularly for routine tasks.

\section{ACKNOWLEDGEMENTS}

The authors would like to acknowledge the financial support provided by the Association of Commonwealth Universities and the British Academy, which helped to support their collaboration. The authors also thank Dr Tertia Barnett, (Northumberland County Council) for sharing their vision for rock-art recording, and, of course, the 50 to 60 volunteers who have been recording petroglyphs in their spare time and have developed their new photogrammetric skills with such enthusiasm.

\section{REFERENCES}

AtKInSON, K.B., 1968. The recording of some prehistoric carvings at Stonehenge. Photogrammetric Record, 6(31): 24-31.

BARNETT, T., 2006. Northumberland and Durham Rock Art Project.

http://pscm.northumberland.gov.uk/pls/portal92/docs/2091.PDF [Accessed 11th December 2006].

BOEHLER, W., HEINZ, G. AND MARBS, A., 2001. The potential of non-contact close range laser scanners for cultural heritage recording. CIPA XIX International Symposium, XVIII-2001, 
Potsdam and IAPRS 34(5C7): 430-436. http://cipa.icomos.org/fileadmin/papers/potsdam/2001 11-wb01.pdf [Accessed 10th August 2006].

BosCH, R., KÜLÜR, S. and GÜLCH, E., 2005. Non-metric camera calibration and documentation of historical buildings. CIPA XX International Symposium, Torino. Pages: 142-7.

BROWN, D.C., 1972. Calibration of close-range cameras, International Archives of Photogrammetry, 19(5): 26 pages: 4.

Cardenal, J., Mata, E., Castro, P., Delgado, J., Hernandez, M. A., Perez, J. L., Ramos, M. and TORRES, M., 2004. Evaluation of a digital non metric camera (Canon D30) for the photogrammetric recording of historical buildings. International Archives of Photogrammetry, Remote Sensing and Spatial Information Sciences, 35(B5): 564-569.

CHANDLER, J. H. and CLARK, J. S., 1992. The archival photogrammetric technique: further application and development. Photogrammetric Record, 14(80): 241-247.

Chandler, J. H., Buffin-BÉlAnger, T., RiCE, S., REID, I. and GRAHAM, D. J., 2003. The accuracy of a river bed moulding/casting system and the effectiveness of a low-cost digital camera for recording river bed fabric. Photogrammetric Record, 18(103): 209-223.

CHANDLER, J.H. and FRYER, J.G., 2005. Recording aboriginal rock art using cheap digital cameras and digital photogrammetry. CIPA XX International Symposium, Torino. Pages: 193-8.

ChandLER, J. H., FrYER, J. G. and JACK, A., 2005a. Metric capabilities of low-cost digital cameras for close range surface measurement. Photogrammetric Record, 20(109): 12-26.

CHANDLER, J. H., FRYER, J. G. and KNIEST, H. T., 2005b. Non-invasive three-dimensional recording of Aboriginal rock art using cost-effective digital photogrammetry. Rock Art Research, 22(2): 119130.

ClogG, P., DíAZ-AndREU, M. and LARKMAN, B., 2000. Digital image processing and the recording of rock art. Journal of Archaeological Science, 27(9): 837-843.

El-Hakim, S. F., Beraldin, J.-A., GonZO, L., Whiting, E., Jemtrud, M, and VAlZano, V., 2005. A hierarchical 3D reconstruction approach for documenting complex heritage sites. CIPA $X X$ International Symposium, Torino. Pages: 790-5.

ENGLISH HERITAGE, 2005. Discovering the past shaping the future, research strategy 2005-2010. http://www.english-heritage.org.uk/upload/pdf/Research_Strategy.pdf [Accessed 10th August, 2006].

FRYER, J. G., CHANDLER, J. H. and EL-HAKIM, S.F., 2005. Recording and modelling an aboriginal cave painting : with or without laser scanning? 3D Virtual Reconstruction and Visualization of Complex Architectures, Mestre-Venice, Italy. http://www.commission5.isprs.org/3darch05/pdf/3.pdf [Accessed 10 August, 2006]

Goskar, T.A., CARTY, A., CripPs, P., BrAYNE, C. and VICKERS, D., 2003. The Stonehenge Lasershow. Archaeology, 73. http://www.britarch.ac.uk/ba/ba73/feat1.shtml [Accessed 10th August, 2006].

GRÜN, A., REMONDINO, F. and ZHANG, L., 2004. Photogrammetric reconstruction of the Great Buddha of Bamiyan, Afghanistan. Photogrammetric Record, 19(107): 177-199.

GrussenMeYer, P., HANKe, K. and STREILEIN, A., 2001. Architectural photogrammetry. Chapter in Digital Photogrammetry. (Eds. Y. Egels and M. Kasser). Taylor and Francis, London. 351 pages: 300-339.

KenEFICK, J. F., GYER, M. S. and HARP, B. F., 1972. Analytical self-calibration. Photogrammetric Engineering, 38(11): 1117-1126.

LeICA GEOSYSTEMS, 2005. Leica Photogrammetry Suite Project Manager User's Guide. Leica Geosystems Geospatial Imaging, LLC, Norcross, USA. 378 pages.

LETELLIER, R., 2001. Bridging the gap between information user and information provider. CIPA 2001 International Symposium, Potsdam and IAPRS 34(5C7): 13-18. http://cipa.icomos.org/fileadmin/papers/potsdam/2001-05-rl01.pdf [Accessed 10th August, 2006].

NeUBAUER, W., Doneus, M., StudNICKA, N. and RIEGL, J., 2005. Combined high resolution laser scanning and photogrammetrical documentation of the pyramids at Giza. CIPA XX International Symposium, Torino. Pages 470-5.

OGLEBY, C. L., PAPADAKI, H., ROBSON, S. and SHORTIS, M. R., 1999. Comparative camera calibrations of some "off the shelf" digital cameras suited to archaeological purposes. International Archives of Photogrammetry and Remote Sensing, 32(5/W11): 69-75.

OGLEBY, C.L, 1999. From rubble to virtual reality: photogrammetry and the virtual world of ancient Ayutthaya, Thailand. Photogrammetric Record, 16(94): 651-670. 
OGLEBY, C.L. and RIVETT, L.J., 1985. Handbook of heritage photogrammetry. Australian Government Publishing Service, Canberra. 115 pages.

OGLEBY, C.L., 1995. Advances in the digital recording of cultural monuments. ISPRS Journal of Photogrammetry and Remote Sensing, 50(3): 8-19.

Palumbo, G., and OGLeBY, C.L., 2004. Heritage at risk and CIPA today: a report on the status of heritage documentation. International Archives of Photogrammetry Remote Sensing and Spatial Information Sciences, 35(5): 839-841.

PATIAS, P., 2007. Cultural heritage documentation. Chapter 9 in Applications of $3 D$ measurement from images (Eds. J.G. Fryer, H. Mitchell and J.H. Chandler). Whittles, Caithness (in press).

PeIPE, J. and StePhani, M., 2003. Performance evaluation of a 5 megapixel digital metric camera for use in architectural photogrammetry. International Archives of Photogrammetry, Remote Sensing and Spatial Information Sciences, 34(5/W12): 259-261.

REMONDINO, F. and EL-HAKIM, S., 2006. Image-based 3D modelling: a review. Photogrammetric Record, 21(115): 269-291.

RIVETT, L.J. 1983. The application of photogrammetry to the recording of rock-art and archaeological sites in the Kakadu National Park. Australian National Parks and Wildlife Service, Special Publication 10: 87-126.

ROSENFELD, A., 1988. Rock-art conservation in Australia. Australian Government Publishing Service, Canberra. 78 pages.

SHORTIS, M. R. and BEYER, H.A., 1996. Sensor technology for digital photogrammetry and machine vision. Chapter 5 in Close Range Photogrammetry and Machine Vision, (Ed. K. B. Atkinson).Whittles Publishing, Caithness. 371 pages: 106-155.

STANBURY, P. and CLEGG, J., 1990. A field guide to Aboriginal rock engravings: with special reference to those around Sydney. Sydney University Press, Sydney. 163 pages.

TOPCON, 2006. http://www.topconsurvey.co.uk/imaging/pi3k.htm\#pi3kp. [Accessed 22nd August, 2006].

WALDHÄUSL, P. and OGLEBY, C., 1994. 3×3-Rules for simple photogrammetric documentation of architecture. International Archives of Photogrammetry and Remote Sensing, 30(5): 426-429.

\section{Résumé}

\section{Zusammenfassung}

\section{Resumen}

